\title{
DRAGONES, CREATIVIDAD \\ Y GENERACIÓN DE CONOCIMIENTO
}

Una consideración modular sobre la Investigación en la Facultad de Derecho

David Valencia Villamizar ${ }^{1}$
Universidad Santo Tomás-Bogotá

Fecha de entrega: 07.02.2014

Fecha de Evaluación: 22.03.2014

Fecha de aprobación: 21.04.2014

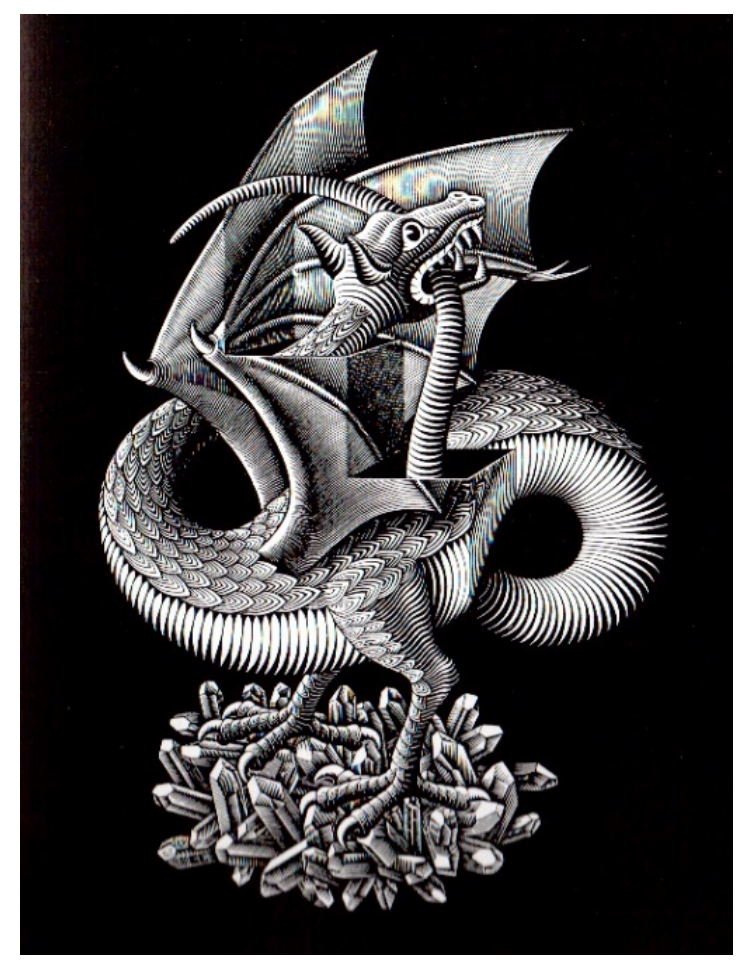

Uroboros, el dragón que se muerde la cola.

M.C.Escher, $1952^{2}$

\footnotetext{
${ }^{1}$ Doctor en Historia, Universidad Nacional de Colombia. Director del Centro de Investigaciones "Francisco de Vitoria", Facultad de Derecho, USTA.

REVISTA VIA INVENIENDI ET IUDICANDI, VOL. 8, No. 2 
Nuestra función como investigadores no es el hallazgo de la verdad sino una crítica del conocimiento.

Virgilio Latorre, Bases metodológicas de la investigación jurídica, 2012, p.172.

Bachelard manifiesta que hacer ciencia o arte implica un ensueño, una seducción, un dejarse capturar de la búsqueda de la verdad, a tal punto que esa seducción empieza a regir la vida y a darle sentido al existir Proyecto Investigativo Institucional (PROIN), USTA, 2005, p. 46.

\section{RESUMEN}

El presente artículo constituye, desde un enfoque alternativo de comprensión del Derecho, una porpuesta, que aborda las cuestiones esenciales sobre los procesos de investigación en el Derecho, especialmente aquellos realizados en la Facultad de Derecho de la Universidad Santo Tomás, caracterizador por su modularidad.

\section{PALABRAS CLAVE}

Investigación, la investigación jurídica, la epistemología y el método de la investigación jurídica, modelo modular.

\section{ABSTRACT}

\footnotetext{
${ }^{2}$ Alegoría o representación de la circularidad de todo proceso investigativo, desde la autopoiesis del problema inicial, pasando por el efecto enciclante o en bucle de la búsqueda, la reflexividad inherente al recorrido, hasta la auto-referencia fractal del despliegue del proyecto inicial.

REVISTA VIA INVENIENDI ET IUDICANDI, VOL. 8, No. 2 
This article shows, from an alternative optic to understanding the Law, a proposal, wich analyzes the fundamental issues of legal research, especially in the Faculty of Law of the Santo Tomás University, that is characterized by his modular system.

\section{KEY WORDS}

Research, legal research, philosophical basis and method of legal research, modular system.

\section{Introducción}

No es un adorno la imagen que abre este artículo. Investigar está ligado siempre a la auto-comprensión de los propios hábitos cognitivos. Por eso el ardid circular del dragón que se consume a sí mismo, aludiendo al darse cuenta de la precariedad de cualquier enfoque, el punto ciego en cualquier perspectiva o a la capacidad de ser consciente de los límites de la forma establecida de ver el mundo.

Si existe un modelo de investigación en la Facultad de Derecho, aquí se busca justificar epistemológicamente dicha estructura, entendiendo que en la formulación de unas políticas de investigación confluyen aspectos procedimentales y de reflexión teórica sobre esos mismos postulados ${ }^{3}$. Tal reflexión no acontece de manera retardada o inconexa respecto de las acciones concretas que emprenden los investigadores, ni como un ornamento que simplemente abstrae o complejiza una práctica, más bien se trata de una dimensión concomitante e imprescindible en el ámbito fecundo y abismal que es la creación de conocimiento.

Esta dimensión creativa tampoco podrá ser reglada de forma exhaustiva. Las indicaciones e intuiciones dispersas en este documento buscan ser un trampolín que potencie la diversidad, pluralidad y multiplicidad de enfoques y aproximaciones a

\footnotetext{
${ }^{3}$ Ver la parte "sobre el marco teórico" en este mismo documento.

REVISTA VIA INVENIENDI ET IUDICANDI, VOL. 8, No. 2

UNIVERSIDAD SANTO TOMÁS, BOGOTÁ

ISSN 1909-0528
} 
determinada temática del saber jurídico. Tal apertura está inscrita en el corazón del sistema modular y es un principio fundamental del Proyecto Investigativo de la Universidad (PROIN). Sin embargo, atendiendo la atmósfera ineludible, que es el conflicto armado en nuestro país, tal campo problemático abre en abismo posibilidades de indagación y metodologías concretas en la articulación de la academia y un insoslayable (y des-construible) contexto social.

Particularmente en el campo del Derecho, con su pretensión de cientificidad siempre por alcanzar, como el dragón en la imagen, la objetividad científica es algo que constantemente elude a los investigadores. En el jugueteo de tal intento se generan parámetros y directrices de investigación. Aquí se busca aportar criterios de orientación básicos en ese girar sobre sí mismo del discurso que busca la verdad, la correspondencia veraz con los hechos, o el extrañamiento de lo novedoso o nunca pensado.

El trauma del conflicto armado, la desmemoria como política de Estado, la tragedia de las víctimas, el anhelo de la paz y en general el análisis del contexto social colombiano, no pueden estar ausente en la investigación de la Facultad de Derecho. Y no por un mera preferencia temática de los diseñadores de ambientes académicos, directivos o sociólogos del conflicto, sino porque ese es el ambiente físico y semiótico que obligadamente respiramos ${ }^{4}$. No se trata de imponer un problema y un estilo metodológico, sino de crear horizontes frente al cual se potencie la creatividad de los investigadores.

\footnotetext{
${ }^{4}$ De acuerdo a las intuiciones Peter Sloterdij en el tercer tomo de Esferas: "en estos campos se desarrollaron atmotécnicas concretas, sin las que no serían imaginables formas modernas de existencia tanto en contextos urbanos como rurales: la popularización de los antes lujosos y señoriales parasoles y paraguas; la instalación de calefacción y ventilación en casas privadas y grandes edificios; la regulación artificial de temperatura y humedad del aire en salas de estar y almacenes; la colocación de neveras en viviendas y la implantación de cámaras frigoríficas fijas o móviles para el transporte y la conservación de alimentos; la política de higiene del aire para entornos laborales en fábricas, minas y edificios de oficinas, y finalmente, la modificación aromático técnica de la atmósfera, con la que se cumple el tránsito al air design agresivo" (Sloterdijk, 2009: 140, cursiva añadida).
} 
De acuerdo a esto, este protocolo opera como una matriz de proyectos de investigación al delinear los criterios y horizontes a tener en cuenta en su elaboración, seguimiento y evaluación. Casi como un macro-proyecto él mismo, pero muy consciente de los espinosos bordes que aureolan su acercamiento al conocimiento y al conocimiento jurídico en particular.

La Facultad de Derecho propugna por el desarrollo de una investigación original, transdisciplinaria y con capacidad de recrear el derecho vigente (de iure condito) ${ }^{5}$ e imaginar y proponer nuevo derecho (de iure condendo). Tal abordaje incluso permite una pesquisa crítica respecto a la validez del conocimiento científico, allí donde en tanto práctica argumentativa el Derecho problematiza nociones recibidas de "objetividad" o "neutralidad" en la práctica investigativa ${ }^{6}$. Como la alegoría del dragón, que nunca puede cerrar o definir de forma absoluta y perfecta sus postulados y principios rectores, condenado así a la proliferación incesante de perspectivas e interpretaciones sobre lo que es el Derecho.

Esta apertura e incompletud es justamente lo que permite la emergencia de investigaciones, aquello que posibilita la aparición de lo nuevo. En esta óptica lo que significamos por Derecho no se reduce al orden normativo, la jurisprudencia o la doctrina, sino que también involucra prácticas, imaginarios, lógicas, marcos cognitivos y modos de pensamiento (Kahn, 2001).

El sistema modular, que da identidad pedagógica y curricular a nuestra Facultad, busca constituir campos de relación entre contenidos temáticos del conocimiento jurídico. La imagen auto-referencial del dragón, de nuevo, sirve de ícono a este anhelo hiperconectivo. Lo anterior no solo se expresa en el plan de estudios del programa de

\footnotetext{
${ }^{5}$ Cfr. Revista Módulos, № 54 (2006: 25, 31,34), donde se caracterizan estas expresiones latinas.

6 "Para los Estudios Críticos del Derecho, la neutralidad política y el objetivismo promovidos por el Estado de derecho liberal occidental son insostenibles, toda vez que el derecho y la ciencia jurídica son categorías determinadas por la política y la ideología" (Fitzpatrick, 2010: 21).

REVISTA VIA INVENIENDI ET IUDICANDI, VOL. 8, No. 2 
Derecho, sino que permea la práctica evaluativa en la realización de un examen modular interesado precisamente en potenciar una mirada relacional y compleja ${ }^{7}$.

El doctorado en Derecho de la Universidad Santo Tomás, propone un esquema investigativo que despliega el potencial de este enfoque modular, el cual se materializa en tres momentos propios del método prudencial tomista: Ver, Juzgar y Actuar, correspondiendo cada uno de ellos a los conceptos de Materia Modular, Centro de Interés y Eje Temático ${ }^{8}$. Articulación de ideas que permitirá tender puentes y buscar maridajes entre ideas más que separar o compartimentalizar datos y puntos de vista sobre el Derecho.

Ya el Documento Maestro del Doctorado en Derecho advertía sobre la especificidad de esta metodología de enseñanza-aprendizaje referida al programa de estudios jurídicos en nuestra Facultad:

"Es el único programa organizado en el país con el sistema modular, conforme al cual la definición de la malla curricular, de los seminarios y de las ciencias y disciplinas convocadas para intervenir en el programa, obedecen a núcleos problemáticos que se relacionan con un específico campo del saber jurídico. El sistema modular es la característica más representativa de los programas de educación tomasinos y es exclusiva de la institución como consecuencia de su asunción de la concepción gnoseológica de Santo Tomás de Aquino" (Documento maestro Doctorado en Derecho: 18).

Adicionalmente, en consonancia con el principio de la filosofía tomista de la quaestiodisputatio (cuestionamiento y disputa, Revista Módulos siglo XXI, 2002), el eje

\footnotetext{
${ }^{7}$ Sobre la Evaluación en la Facultad de Derecho, siempre de acuerdo a los principios del sistema modular, ver la citada Revista Módulos (2006, passim).

${ }^{8}$ Cfr. Revista módulos $N^{\circ} 42$ "Introducción general al sistema modular", en Núcleos Problemáticos, USTA, Bogotá, 2002.
}

REVISTA VIA INVENIENDI ET IUDICANDI, VOL. 8, No. 2 
VALENCIA V., DAVID (2013): “DRAGONES, CREATIVIDAD Y GENERACIÓN DE CONOCIMIENTO: UNA CONSIDERACIÓN MODULAR SOBRE LA INVESTIGACIÓN EN LA FACULTAD DE DERECHO”, VIA INVENIENDI

ET IUDICANDI, VOL. 8, No. 2, PP. 110-136

$\overline{\text { vertebrador de los procesos investigativos de la Facultad estará dado por la crítica }{ }^{9} \text { a }}$ los postulados medulares y a la realidad social en que tales premisas se desenvuelven.

Para lograr las metas propuestas en la formulación, gestión y evaluación de proyectos, según las ideas antes expuestas, no bastará simplemente con poseer información, ni manejar datos o conocimientos de forma mecánica. Tampoco será suficiente con tener experiencia en el litigio o el ejercicio de alguna magistratura. Hará falta también dejarse seducir por el objeto de investigación ${ }^{10}$ (Baudrillard, 1998), como para el psicoanálisis lacaniano, es el carácter paradójico, resbaloso y permanentemente inasible del objeto lo que lo torna atractivo, y más en escenarios normativos que pretenden desligarse de dimensiones instintivas, emocionales y afectivas que siempre retornan para inquietar las posturas más científicas u objetivas. Si lo reprimido vuelve a manera de síntoma, en el campo jurídico tales dimensiones de la experiencia también hacen digno de investigar un tópico o constelación temática dada. Este espesor de fascinación de la búsqueda es insoslayable, de tal suerte no puede hablarse de investigación sin aludir, al menos en la metáfora, al abismo sobrecogedor de arrojarse a una pesquisa en cualquiera de los niveles de formación. Ese vértigo resulta pulsionalmente fecundo y no podemos eludirlo en una consideración preliminar sobre cualquier proceso investigativo.

Perfilar habilidades investigativas concretas según lo apuntado, no es algo que tenga que ver con un mayor o menor acercamiento a los "hechos", la "verdad" o la "realidad"11, sino a la capacidad de fabular un relato plausible, una hermenéutica

\footnotetext{
${ }^{9}$ Enfatizamos que crítica se declina aquí en la conmoción de una crisis que obliga al replanteo de lo dado por descontado, crisis de la modernidad, crisis de los meta-relatos, crisis humanitaria, crisis ecológica y social, todas ellas dejan de ser lugares comunes para transmitir al pensamiento la urgencia terrible del desastre y el desfonde epistemológico que innegablemente implica.

${ }^{10}$ Este principio es un desarrollo del Proyecto Investigativo de la Universidad: "lo interesante no es lo que se busca o lo buscado, sino el proceso de búsqueda, un proceso en el cual el investigador seduce y se deja seducir" (PROIN, 46).

${ }^{11}$ Se aclara que con respecto a la investigación socio-jurídica la mirada que se cierne sobre la "realidad social" siempre está mediada por el sistema de signos usados para significarla, no pude haber un acercamiento desnudo o "puro" a la realidad, la perspectiva del sujeto es ineliminable. Lo que ocurre es que de acuerdo a relaciones de poder
}

REVISTA VIA INVENIENDI ET IUDICANDI, VOL. 8, No. 2 
verosímil, un específico punto de vista. Se relativizan así distinciones tajantes entre "ficción" o no "ficción", esto lo ha expresado de manera ejemplar el autor de El análisis cultural del Derecho:

"Una aproximación cultural ve que todos los textos del derecho son trabajos de ficción. Cada uno sostiene un mundo creado por la imaginación al presentarlo como nuestro mundo. Para cada uno de esos mundos imaginados podemos, y frecuentemente lo hacemos, imaginar mundos alternativos. El giro hacia la literatura de ficción no es, entonces, un giro para alejarse del derecho, sino sólo otra forma de examinar el carácter construido de nuestro universo político y de nuestra identidad al interior de ese universo" (Kahn, 2001: 170).

La investigación será la articulación narrativa de un cierto "túnel de realidad". Bajo este criterio, el Derecho es un constructo interpretativo privilegiado, tan imaginario como cualquier otro armadijo semiótico pero con efectos de realidad bien patentes, a veces atroces. De esta manera, investigar será siempre investigarse, como nos enseña la sensibilidad de nuestro sistema modular. Vivimos en unas coordenadas de sentido y unos códigos lingüísticos que determinan lo que es real y lo que es ficción, funcionan como una matriz de significados social y culturalmente disponibles a partir de los cuales toman consistencia ideas sobre el "yo", el "tiempo" y el "espacio" : "el Estado de derecho es una práctica social: es una forma de ser en el mundo. Vivir bajo el Estado de derecho es mantener un conjunto de creencias sobre el yo y la comunidad, el tiempo y el espacio, la autoridad y la representación" (Kahn, 2001: 53). Investigar tiene que ver con la constatación del mundo del Derecho como arquitectura conceptual que da solidez a nuestra experiencia de lo real, y no con la naturalización de esos

se validan ciertos contextos y enfoques sobre otros. Tales mecanismos de legitimación son los que deben ser evidenciados en el proceso investigativo. 
esquemas como algo incuestionable ${ }^{12}$ : "al estudiar el Estado de Derecho el investigador está estudiando la estructura de sus propias creencias: las condiciones conceptuales y las condiciones de la imaginación del mundo dentro del cual presenta argumentos de verdad o falsedad, bondad o maldad" (Kahn, 2001: 183).

Lo que quiere señalarse la posibilidad de enriquecer la mirada desde estos postulados sobre la investigación y el diseño y ejecución de proyectos. Proponemos así un punto de vista que amplía el horizonte exclusivamente científico ${ }^{13}$ para pensar la investigación en Derecho. Tales criterios de cientificidad ${ }^{14}$ se verían enriquecidos con una postura como la que aquí se discute, como ocurrió con la mecánica clásica newtoniana al momento de surgir la física cuántica, las ciencias del caos o la complejidad. Estas últimas no niegan sino que ensanchan las posibilidades cognitivas preexistentes.

\section{El investigador es la red}

\footnotetext{
12 "Para entender el poder del derecho tenemos que dejar de observar tanto a los mandatos de las instituciones jurídicas y empezar a mirar la imaginación jurídica" (Kahn, 2001: 181)

${ }_{13}^{13}$ Para una genealogía del "giro científico" en los estudios de doctorado en Derecho ver (Martinez y Pujol, 2008).

${ }^{14}$ Así reza la revista que explicita el "módulo de investigación" de la Facultad de derecho: "como nos recuerda Giddens, el gran error de los positivistas sociales fue tratar de aplicar el método de las ciencias de la naturaleza a las ciencias sociales" (Módulos 53: 11).

REVISTA VIA INVENIENDI ET IUDICANDI, VOL. 8, No. 2 


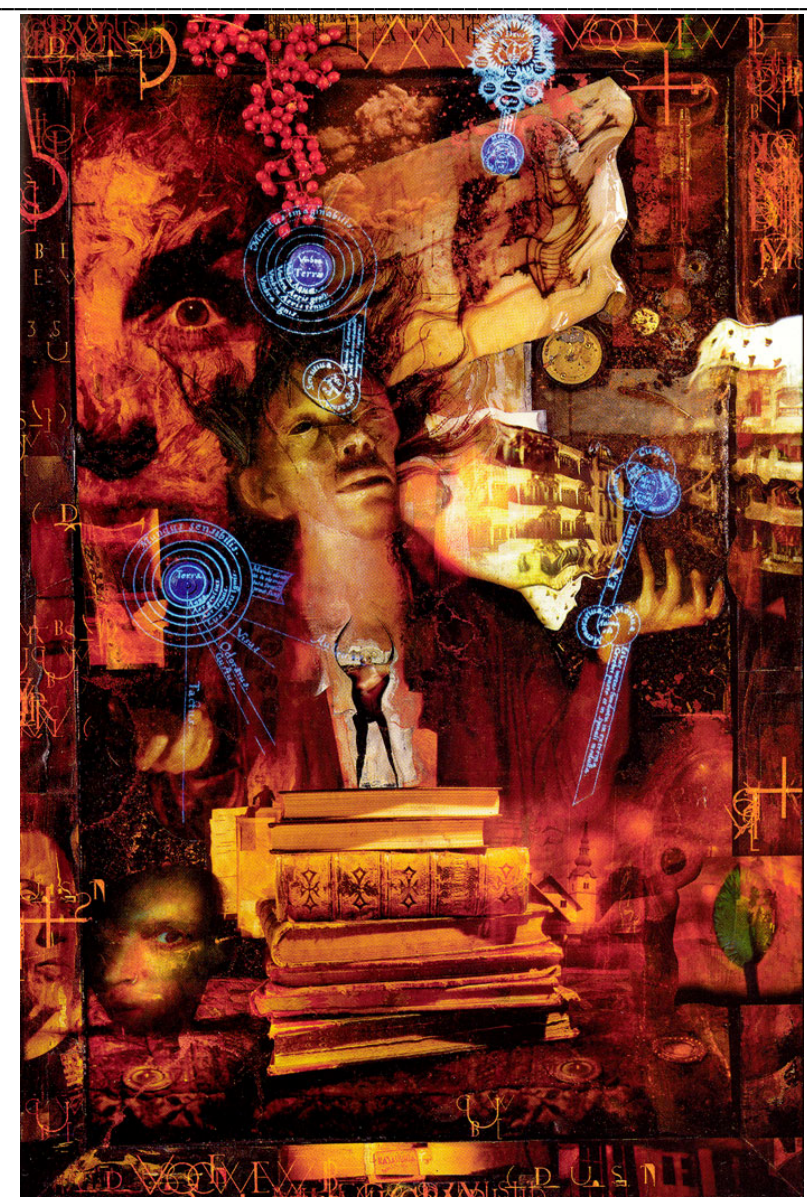

Ilustración de Dave Mckean en que se aprecia la complejidad imaginativa de un proceso investigativo. Imagen disponible en http://www.bleedingcool.com/forums/comicbook-forum/17355-tripping-over-myself-3-joel-meadows-dave-mckean.html

¿Quién es el investigador?, el sujeto es la red, un nodo de asociaciones cognitivas de carácter transpersonal (Deleuze y Guattari, 1997). No el individuo aisladamente considerado, sino la inteligencia de enjambre que se distribuye de manera rizomática y proliferativa entre las identidades institucionalmente construidas. El que piensa son los que piensan, un colectivo cuyos vórtices llamamos o representamos o significamos como "sujetos", pero que en verdad son un nodo interconectivo constante, un umbral a través del cual se ponen en relación empatías temáticas dadas. Por esta interfaz circulan ideas, imágenes, bibliografías, afectos, memorias, intereses o teorías, esquemas metodológicos, deseos, ideales, referencias y otros fragmentos expresivos 
que nunca alcanzan un estado de equilibrio. Se hallan en un devenir permanente $\mathrm{e}$ inagotable, poniendo siempre en peligro las asignaciones de sentido más obvias acerca de "quién" investiga.

Si la metáfora del anfibio académico se torna relevante (Jurado, 2012; Rodríguez, 2013: ), entre contagios, teriomorfias, ambigüedades animóticas y otros raros devenires animales, lo es porque en ella la metamorfosis y la hibridación priman sobre cualquier asignación de esencia. Parafraseando a Eduardo Viveiros de Castro, especialmente su obra Metafísicas caníbales 2010) podríamos decir que la praxis investigativa se constituye en un ejercicio permanente de des-colonización intelectual, teórica y epistemológica-

Así no solo se transita a través de entornos clásicamente divididos entre "derecho" y "sociedad" o "academia" y "campo", sino que se desliza también entre dominios discursivos, formas de conocimiento e incluso cosmovisiones o sensibilidades heterogéneas, como quien transgrede las fronteras en las categorías axiales de nuestra forma de pensamiento. En este sentido, des-construir la archi-manida y no menos raída o manoseada dicotomía "teoría" y "praxis" es ya un privilegio de estos anfibios indagadores, sean activistas o no.

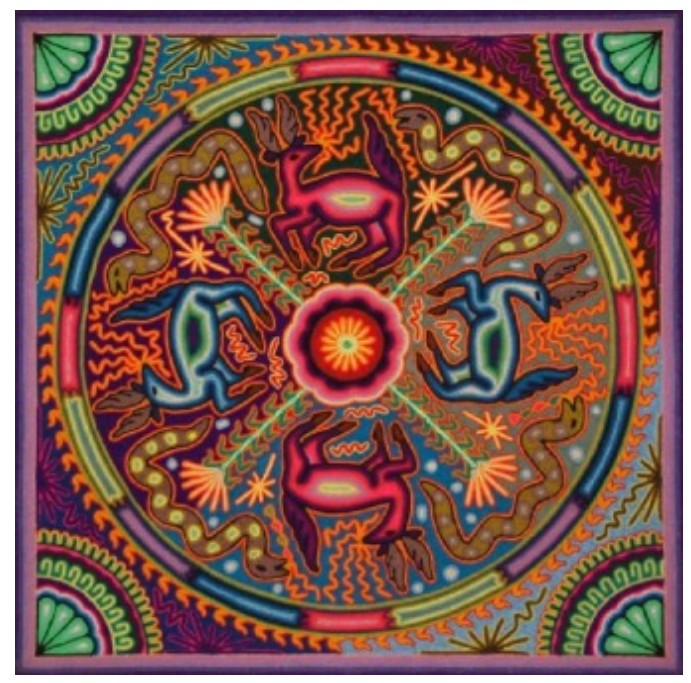




\section{Representación cosmológica del mundo Huichol, norte de México}

\section{Objetivos siempre hipotéticos}

Resulta tópico e incluso redundante insistir en la importancia de ubicar con claridad los objetivos de un trabajo investigativo, no lo es significarlos como transformables, plásticos y metamórficos. Es decir, privilegiamos aquí la mutación creativa antes que la inmovilidad condescendiente. Esta maleabilidad no riñe con su carácter orientador, al revés, asumirlos como algo en devenir les da vida y los hace más plausibles de servir de pauta y guía.

Una compilación de avances parciales de tesis doctorales, resumía así las diferentes aspiraciones y objetivos de los trabajos:

"[los artículos] todos son el resultado de esfuerzos investigativos realizados tanto desde la metodología histórica como desde la sociología para intervenir en diferentes campos del análisis legal, bien evidenciando historias alternativas de las categorías legales tradicionales o bien mostrando cómo opera el derecho en contexto construyendo realidades, posicionando actores $y$ distribuyendo recursos" (Alviar, 2012, 48).

En esta diversidad de enfoques se percibe la multiplicidad que compone el arpegio temático, ligado siempre a la formulación de los objetivos de investigaciones en el mundo jurídico. Lo que interesa resaltar es, que a lo largo de la búsqueda, los objetivos pueden sufrir mutaciones creativas, perdiendo así algún carácter apodíctico o de innegociable camisa de fuerza. De hecho, la modulación temporal de los objetivos es deseable en un trabajo que se abre a los devenires no-lineales y pulsionales del 
investigador (Zizek, 2009). Como se sostenía en la presentación, sin seducción no hay investigación. Y la seducción es un magnetismo indescifrable, imposible de encorsetar de forma definitiva, o explicar solo desde una angulación científica o lógica.

Llevando estas ideas más lejos, diríamos que negar la seducción es impedir la emergencia creativa de ideas desacostumbradas, no sospechadas o inéditas. De ahí que, si bien los objetivos señalan derroteros y líneas de afección sensorial posibles, también estimulan el rediseño constante de sus límites: la reimaginación incansable de las metas, atendiendo además modificaciones en los contextos, los cambios biorítmicos y la redefinición de las prioridades, la aparición de nueva bibliografía, etc (Morin, 1997).

No desconocemos, al plantear esto, que "todo trabajo de investigación será evaluado, entre otros aspectos, por el logro de los objetivos que se ha propuesto" (Patiño, 2013: 18). Sin embargo, esta evaluación no puede limitarse a una rígida constatación, sino que se muestra sensible al enriquecimiento de los objetivos, aún por fuera de las estrictas coordenadas que se manifiestan en el proyecto.

Este es un punto clave, el proyecto no puede predecir y encasillar todos los desarrollos que como variaciones se desprenden de la propuesta inicial, por lo que aunque trascendental, la formulación concisa de las metas es apenas un santo y seña, una clave, un horizonte que hallará contenido de maneras a veces sorprendentes si el ejercicio es verdaderamente creativo y crítico.

Será en el seguimiento que haga el tutor, director o asesor de investigación que se propicien estas nuevas derivas, por lo que sería un error descalificarlas con el argumento de que no se habían explicitado en los objetivos consignados en el proyecto. La identidad de la criatura (la idea de investigación como ser vivo) cambia y se fecunda en contextos movedizos, afortunadamente muy traslaticios, particularmente 
atendiendo dinámicas sociales y problemáticas con los niveles de complejidad propios del contexto colombiano.

Así las cosas, podemos retomar una idea sobre lo que es propiamente la hipótesis de un proyecto de investigación:

"La hipótesis es una conjetura que predice la respuesta a un problema, cuya veracidad depende de que sea corroborada en la investigación; es la respuesta, explicación o predicción tentativa que tiene el investigador frente a la pregunta de investigación que se formuló al momento de plantear el problema, de manera que si la pregunta contiene una incertidumbre, la hipótesis es su respuesta.

La hipótesis constituye el eje transversal de la investigación y articula todo el proceso investigativo, de manera que este se encuentra al servicio de la corroboración, verificación o falseamiento de aquellas.

Las hipótesis surgen de los objetivos, el planteamiento del problema y las preguntas de investigación y una vez se realiza la evacuación de la literatura que la fundamenta, de manera que, la relación entre estos es muy estrecha" (Patiño, 2013, 18).

La consideración hipotética de un resultado previsible, anticipable o deducible de premisas nos desliza al centro de la matriz positivista de pensamiento, empeñada en un escrutinio de tipo lógico-mecánico sobre los acontecimientos, sensibilidad que autoras afines al feminismo radical han equiparado a una verdadera e impúdica mirada pornográfica: 


\begin{abstract}
"Así, la sexualidad desborda el aspecto meramente físico de su realización y se configura ante todo como una actitud ante el mundo. Por eso, hablar de una mirada pornográfica no envuelve solamente nuestro comportamiento físico sino también nuestra actitud vital. Es una cuestión no solo de sexualidad sino de sensibilidad sexualizada. (...) En este sentido, la mirada pornográfica es una actitud permanente antes que un acto aislado" (MacKinnon, Posner, 1997: 30).
\end{abstract}

El modo de observación de la tecno-ciencia moderna, de acuerdo a esta crítica contenida en la introducción de María Mercedes Gómez al debate de las feministas radicales contra la pornografía, operaría de acuerdo a la misma pulsión escópica: un apetito escudriñador sin límites, hipertrofia del "querer ver" sin reparar en límites morales o cognoscitivos ${ }^{15}$. En resonancia con ideas de Michel Foucault en su Historia de la Sexualidad, se trata de des-construir los dispositivos de sexualización como entornos generadores de identidad, por lo que esta "actitud vital" aparece en escenarios tan alejados de ella como la praxis investigativa ${ }^{16}$, que en su formulación de hipótesis, confirma auto-generadamente los presupuestos analíticos de la epistemología de la ciencia.

Hipótesis porno-cognitiva entonces, apetito irrefrenable por ver en un high definition vertiginoso aspectos insospechados de lo real, impulso que permea entornos académicos donde la supuestamente desapasionada formulación de hipótesis repite inconscientemente motivaciones paradigmáticas de la ciencia experimental. Así tenemos un ejemplo de crítica frente a metodologías recibidas y formas de ver consolidadas y naturalizadas como ya el Proyecto Investigativo institucional proponía:

\footnotetext{
${ }^{15}$ Sobre este punto el excelente libro de Gérard Wajcman (2011), El Ojo absoluto. Donde se escudriña este nuevo régimen de visión, su apetito incesante y la forma como ha reconstituido completamente las políticas de la mirada, las formas de ver, los dispositivos psico-técnicos de apreciación en el mundo contemporáneo

16 "En realidad la pornografía tal y como hoy la conocemos nace con Boyle, con Newton, con Galileo, con Descartes" (Barba y Montes, 2007 : 133), es decir, hay un obsceno parentesco entre el método científico como modo de ver e investigar y la mirada propiamente pornográfica.
}

REVISTA VIA INVENIENDI ET IUDICANDI, VOL. 8, No. 2 
"romper esquemas implica un desprendimiento de lo pre-existente, un alejamiento de lo obvio para pasar a la búsqueda de nuevos horizontes con base en intuiciones y en la búsqueda de oportunidades que hacen que esta realidad se pueda transformar" (PROIN, 47).

\section{Sobre el marco teórico}

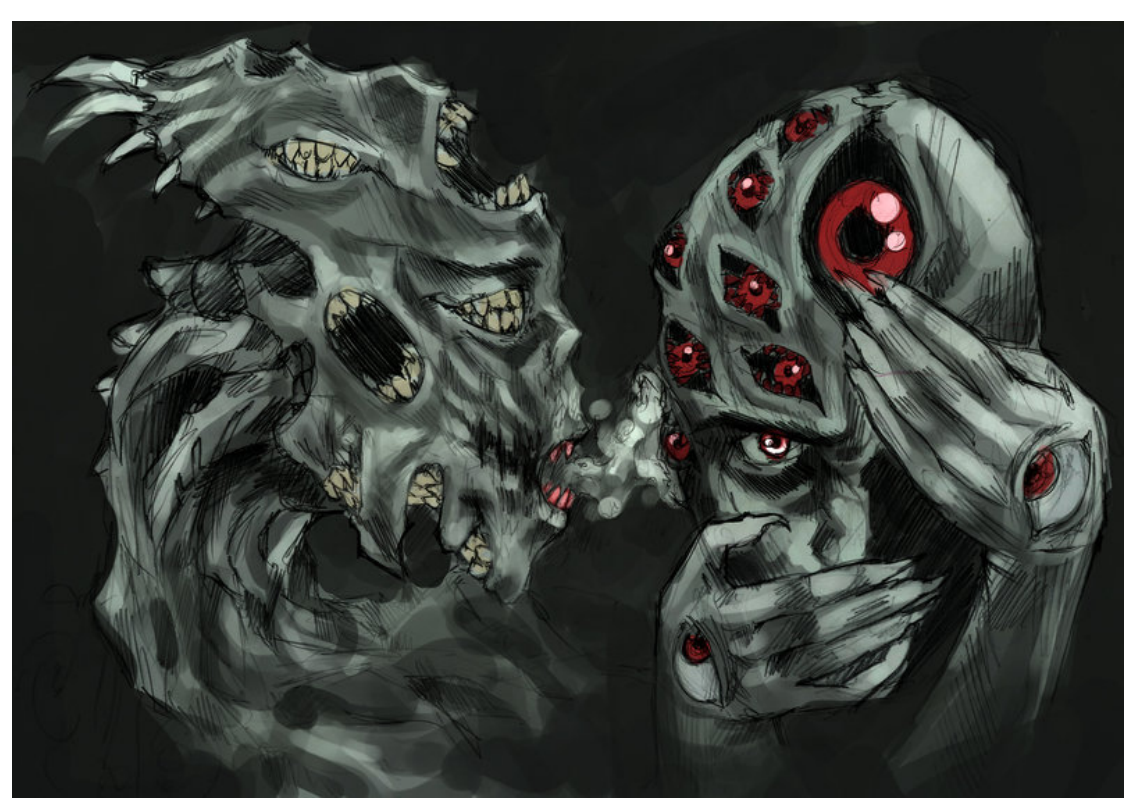

Explicitar las ideas que obsesionan al investigador es lo que constituye el marco teórico de un proyecto. Como un susurro entre tranquilizador y muy agobiante. Imagen tomada de http://theboyofcheese.deviantart.com/art/Whispers-of-Paranoia-114934101

Consideramos que en el ejercicio investigativo, cuyo primer momento es la elaboración del proyecto, se relativizan sobre la marcha distinciones tajantes entre teoría y praxis (Twining, 2003). No hay acción que de alguna manera se desligue de una teoría que le sirve de plano de coordenadas. No hay pragmatismo más exacerbado que no se haga sobre una imagen del mundo que lo antecede y hace posible. 
Aquí la teoría no es una reflexión abstracta o abstrusa que redobla lo que acontece primero en el reino empírico. La teoría son los devenires conceptuales permanentemente activos en cualquier operación cognitiva de los sujetos, sea ésta consciente o no (Kahn, 2001). No podemos prescindir de la teoría como si se tratara de un suplemento, adorno o artificio alejado de la realidad. Lo considerado "realidad" se desprende del enfoque teórico que se maneje.

Desde estas ideas, el marco teórico no es otra cosa que la organizada exposición de las ideas que han fabricado la percepción que se tiene del objeto de estudio. El enfoque cognoscitivo, el sesgo, el ángulo de enunciación que permite la toma de consistencia de una particular forma de definir qué es lo que se llamará "real" o cómo identificar las "cosas" y "sujetos" que lo componen.

Teoría viene de teorein, expresión ligada al desfile o transcurso de imágenes que hacen posible una forma determinada de ver, de aprehender significativamente los estímulos sensibles. Parafraseando la introducción al concepto de "teoría jurídica en acción" (Twining, 2003:25) diremos que no hay diferencia entre una persona teórica o no teórica, sino entre alguien consciente de las filiaciones teóricas que lo animan y alguien que no lo es. Es decir, en todo caso respondemos a condicionantes epistemológicos, el asunto es si lo sabemos o lo ignoramos.

Aterrizando estas nociones al campo del Derecho, tenemos que la desconstrucción o cuestionamiento de la distinción teoría y praxis, según los introductores al volumen Derecho y globalización se tematizaría desde estos presupuestos:

"Por derecho en acción entendemos cuando menos dos cosas: la primera hace referencia a lo local, es decir, a la teoría jurídica que de manera predominante o "hegemónica" explica la práctica jurídica en un contexto determinado 
(Colombia y el positivismo jurídico, por ejemplo) y a la forma como esta teoría dominante opera a través de postulados implícitos en los diferentes papeles legales (...) En segundo lugar, y desde una perspectiva más global, el término "derecho en acción" alude a las dinámicas que se generan entre las "teorías jurídicas transnacionales" y los contextos de producción y recepción de tales teorías" (Twining, 2003, 28-29).

Un marco teórico, desde estas intuiciones, no puede por un lado desconocer las metanarrativas de grandes constructos teóricos (jusnaturalismo, positivismo, realismo jurídico, etc.). Pero tampoco, y esto es fundamental, las formas de contagio y traspaso de tales ensamblajes teóricos de un país a otro, de un contexto a otro, de un "túnel de realidad" a otro.

Ya desprovista la "teoría pura" kelseniana de su aureola impoluta y abstracta, una aproximación seria hacia lo teórico no puede desconocer las dinámicas políticas de traducción y trasplante de ideas sobre el Derecho ${ }^{17}$. El marco teórico de un proyecto investigativo en este campo debe dar cuenta de las relaciones de dominio e intereses que validan una cierta forma de pensar el derecho en detrimento de otras ${ }^{18}$.

Hibridez, mestizaje y mezcla de ideas ${ }^{19}$ van a ser expresiones más afortunadas que completud, racionalidad o corrección teóricas. La urgencia de un enfoque tal se percibe en estas palabras: "no prestar atención a las relaciones entre la teoría y la práctica jurídica en las condiciones actuales de globalización significa continuar fragmentando y

\footnotetext{
${ }^{17}$ Una discusión actualizada de este fenómeno se encuentra en Teoría del Derecho y transplantes jurídicos (Bonilla, 2009).

${ }^{18}$ En un tono provocador, el autor de El Derecho como resistencia califica de infame su despliegue en contextos específicos como Latinoamérica: "en su infamia, el derecho occidental se refleja a sí mismo. Este derecho es interpretado por algunos como infame, debido a su complicidad con la opresión de los pueblos del tercer mundo" (Fitzpatrick, 2010: 47).

${ }^{19}$ Sobre la génesis de las ideas, leemos en el tomo IV del Método: "Hemos aprendido que las ideas se fijan cerebralmente por la estabilización selectiva de las sinapsis, que se inscriben psíquicamente por imprinting, que adquieren vida y potencia noológica alimentándose de nuestras necesidades, deseos, temores, y que nos drogamos con ellas para apaciguar estas necesidades, deseos temores" (Morin, 1998: 250).
}

REVISTA VIA INVENIENDI ET IUDICANDI, VOL. 8, No. 2 
distorsionando el fenómeno jurídico" (Twining, 2003: 27). Esas relaciones entre teoría y práctica, en tanto aproximación sin ingenuidades a los modos como circulan corpus discursivos a nivel trasnacional deben estar presentes en el marco teórico de un proyecto investigativo modular. Y decimos "sin ingenuidad" para evitar de antemano la creencia en enunciaciones neutras que de alguna forma se situarían fuera de estructuras muy concretas de dominación y exclusión de lo divergente, presentes en categorías como "sujeto jurídico", "tiempo" o "espacio":

"Las relaciones coloniales existen y persisten en el orden del discurso, en las nociones y categorías que sustentan el derecho occidental como forma ejemplar de gobierno; por ello se impone la necesidad de desarrollar el pensamiento crítico, justo allí donde el poder quiere hacernos a la vez su objeto e instrumento" (Fitzpatrick, 2010: 45).

Este pensamiento crítico se halla en consonancia con las transformaciones sociales que demanda el perfil del abogado de la Universidad Santo Tomás. Responsabilidad que respecto a los compromisos teóricos que determinarán el posterior desarrollo de la investigación, exige tanto su explicitación como su confrontación con posturas diversas. Dos componentes indiscutibles del marco teórico del proyecto.

Sintetizaríamos argumentando que el marco teórico fabrica un verdadero "túnel de realidad" que posibilita un punto de vista pero que simultáneamente enceguece respecto a otros enfoques. En óptica se habla de "punto ciego" como aquella zona de un dispositivo de observación, biológico o cultural, que abre lo percibible pero que no es percibida ella misma (Morin, 1997). Alumbrar ese sitio o al menos darse cuenta de su existencia, es esencial al formular el marco teórico. 
Adicionalmente es imprescindible la presentación de los moldes teóricos presentes incluso en el abordaje más dogmático o normativo, con el objetivo ambicioso de recrear teorías jurídicas en lo que sería la toma de consistencia de una escuela de pensamiento jurídico en nuestra Facultad de Derecho. $Y$ más teniendo en cuenta la fortaleza que en la Universidad Santo Tomás tiene la Filosofía Latinoamericana. De donde, por ejemplo respecto al llamado "pensamiento indígena" o las discusiones sobre "pensamiento propio" podrían nutrirse enfoques jus-teóricos críticos y situados.

IV. Des-construyendo modularmente la metodología

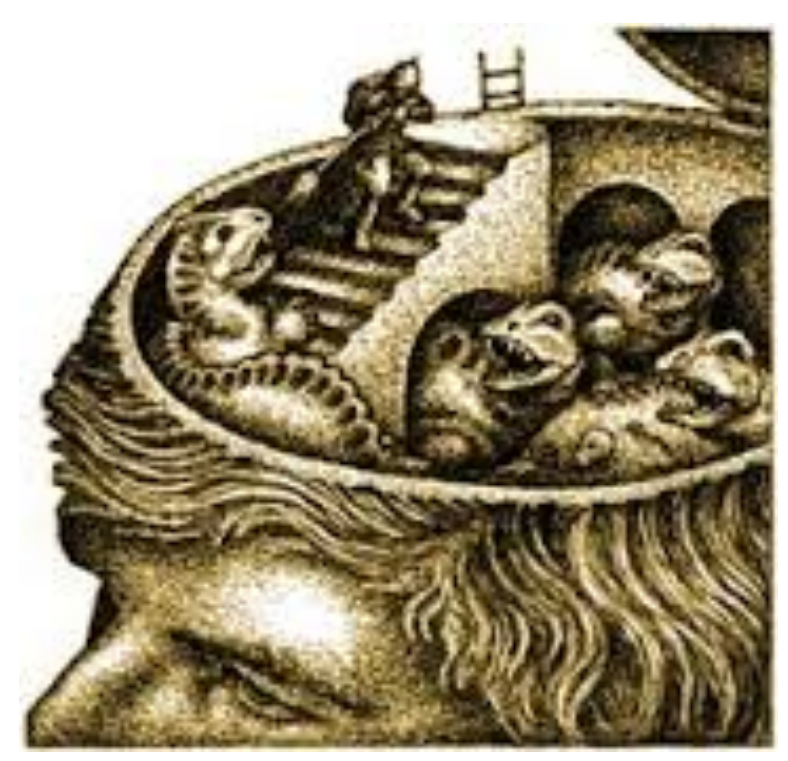

Posible ilustración del funcionamiento, a veces aterrador, de los procesos mentales del investigador (las metodologías aquí son vistas como parásitos mentales). Imagen tomada de http://vivesana.blogspot.com/2010/11/expertos-advierten-sobre-el-aumentode.html

Podemos hablar de dos grandes angulaciones metodológicas en ciencias sociales: las metodologías cualitativas y las cuantitativas. Entendiendo que pueden darse intersecciones y mezclas entre ambos modelos. Para la primera familia metodológica la 
interpretación va a ser la herramienta fundamental, respecto a la segunda, el análisis estadístico será determinante. Esta taxonomía atiende la especificidad del Derecho como práctica discursiva antes que como ciencia con leyes universales. Enriquecer la visión le Derecho desde la hermenéutica, permite ampliar enfoques meramente numéricos o cerradamente positivistas y dogmáticos. El formalismo extiende sus alas y vuela, implicando criterios de recolección y análisis de datos menos rígidos. Si el Derecho es ciencia lo es de una manera muy peculiar, más afín a las intuiciones de la ciencia de la complejidad, la dinámica de sistemas no-lineales, la geometría fractal o la teoría del caos.

Hoy en día la ciencia se nutre del principio de incertidumbre, de las perplejidades de la relatividad o de la mecánica cuántica. Ampliando así el mecanicismo que sirvió de modelo en el diseño de metodologías que asumen el privilegio de ser "científicas". En este apartado serán traducidas estas pistas de una ciencia jovial ${ }^{20}$, irreductible a criterios hegemónicos de "objetividad", en el ensamblaje procedimental que es la metodología de investigación ${ }^{21}$.

No olvidemos que con relación al seguimiento procedimental o metodológico "el investigador juega libre y puede adoptar incluso una posición más atrevida" (Latorre, 2012: 172), en el sentido que hablábamos de los objetivos como algo en transformación, cambio y devenir. Mutación no solo no condenable sino propicia y fecunda para abrir variaciones en el esquema de operaciones de la investigación, esta idea se realiza de acuerdo a metodologías abiertas, sensibles a la aparición de lo imprevisto. No nos cansamos de resaltar esta dimensión ya que desde el enfoque modular es tenida por cardinal.

\footnotetext{
${ }^{20}$ En el sentido que Friedrich Nietzsche le da a la expresión, como ciencia dionisíaca y artista, consciente de sus límites y dispuesta a trazar la espinosa genealogía de sus compulsiones interpretativas y valorativas más básicas.

21 "Lo que enseña a aprender, eso es el método. No aporto el método, parto a la búsqueda del método" (Morin, 1997, 35)
}

REVISTA VIA INVENIENDI ET IUDICANDI, VOL. 8, No. 2 
Insistir en la rígida compartimentalización o tabicación de momentos metodológicos, como quien traslada del proceso judicial la lógica y la secuenciación de los pasos a la investigación, es ahogar la dimensión creativa de los procesos investigativos. Recordemos que la racionalidad del proceso ha dado lugar a críticas tan lúcidas como la planteada por Franz Kafka en el conjunto de su obra, pero especialmente en ese delirio de laberintos y espejos de una burocracia aplastante que es El Proceso. Los abogados tendrían mucho que aprender de esta obra, recordemos lo que nos enseña sobre esto el Análisis Cultural del Derecho:

"Para asir adecuadamente el carácter competitivo del límite entre el derecho y lo que no es derecho, tenemos que girar a otros textos característicos incluyendo la literatura de ficción. En la literatura de ficción, la cultura del derecho surge como una forma de poder: el poder de mantener la imaginación de un lado de la frontera, antes que del otro" (Kahn, 2001: 169).

La metodología, desde aquí, no puede perpetuar esta condena imaginativa que reproduce una cultura del Derecho alucinada con la idea de un único modo -jurídico- de hacer las cosas, de ordenar las relaciones sociales, de sentir o de soñar. En vez de ello debe investigar las formas de poder que inviste ese intento asfixiante, para eso debe servir una metodología, para procedimentalizar el desnudamiento de condiciones de burocratización, codificación y control de la vida en todos sus aspectos.

Correlacionando Método y ejercicio libertario, nos dice Edgar Morin: "En el origen, la palabra método significaba el caminar (...). El método no puede formarse más que durante la búsqueda; no puede despejarse y formularse más que después, en el momento en que el término viene a ser un nuevo punto de partida, esta vez dotado de método" (Morin, 1997: 36). Como si prefigurar con pretensiones de completud el método investigativo fuera equivalente a impedir el desarrollo mismo de la búsqueda. 
Desde estas intuiciones, listar los métodos y las perspectivas investigativas en general sería artificioso, preferimos dejar planteadas estas ideas a manera de bosquejo y suscitar que al recorrer modularmente las singularidades de cada pesquisa sean adaptados ensamblajes y sensibilidades múltiples.

\section{Conclusiones infinitivas}

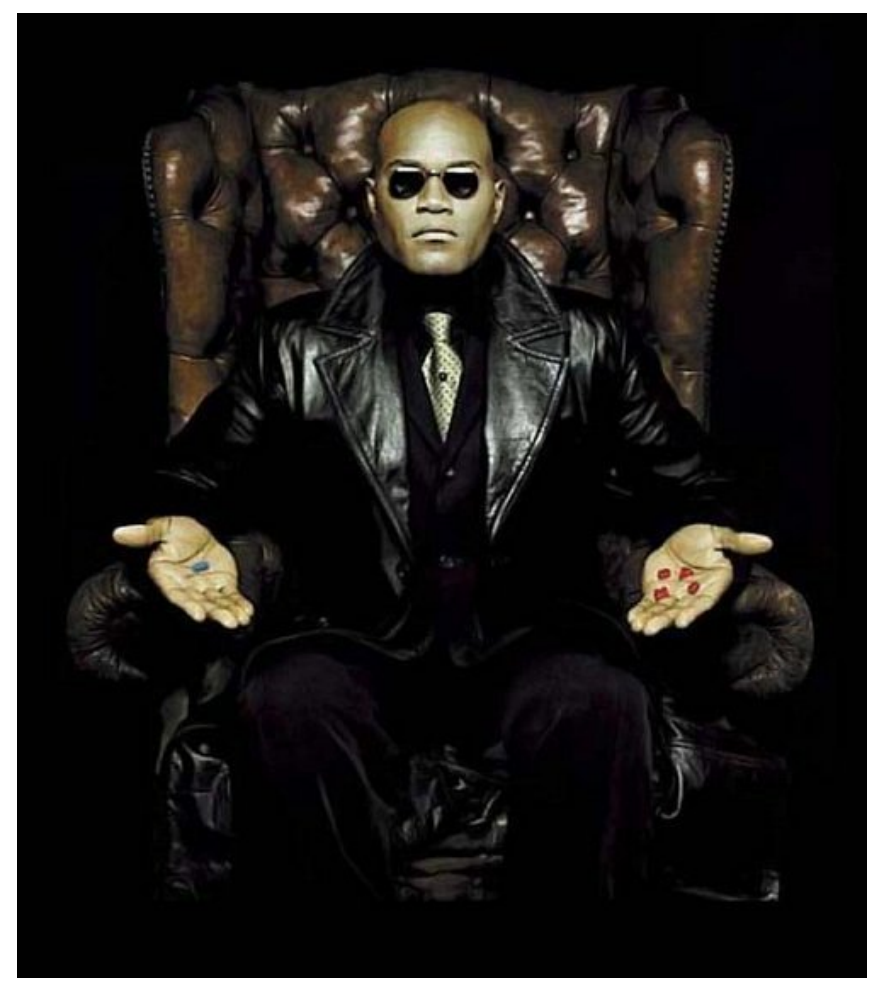

La famosa elección de Morpheus en la película Matrix, ejemplifica para nosotros el arrojo y valentía epistémica implicada en un proceso modular de creación de conocimiento.

Modificar nuestros hábitos de pensamiento asociados al ejercicio investigativo fue el propósito nuclear de este texto. Valiéndonos de imágenes alusivas a la circularidad y 
auto-referencialidad de toda pesquisa insistimos en el carácter perspectivo de nuestra forma de producir conocimiento.

Con ideas tomadas del Análisis Cultural del Derecho quedó claro que vivimos y recreamos un mundo de significados históricamente configurado y no una realidad ontológicamente fija.

Posibilitar la recombinación crítica de esa red de sentido fue el reto asignado a la investigación. Adicionalmente la metodología y el enfoque de nuestro sistema modular sirvieron de catalizadores para soportar las anteriores afirmaciones. De la misma forma, el principio de seducción y el carácter transformativo (tanto del sujeto como del objeto de la búsqueda) fueron principios cardinales en nuestras afirmaciones.

Atreverse a tomar la pastilla roja y maravillarse $u$ horrorizarse (o ambas a la vez) con la profundidad abismal y fecunda del agujero del conejo, de acuerdo a la metáfora de la caída de Alicia en el país de las maravillas de Lewis Carroll (sugerente o eróticamente usada en la película MATRIX, de los hermanos Wachowsky), fue el impulso que animó la redacción de este artículo. Des-construir dicotomías graníticas o tenidas por inamovibles, como sujeto/objeto o teoría y praxis, también hizo parte de este mismo intento.

El contagio de ideas sobre el Derecho, el transplante de fragmentos jus-teóricos, el sujeto-red, los anfibios académicos, la porno-cognición racionalista entre otros conceptos e insinuaciones, desfilaron para maridar aportes de la literatura, la filosofía, el sicoanálisis o el análisis del discurso, en una consideración sobre el sentido de la investigación en la Facultad de Derecho de la Universidad Santo Tomás.

\section{Referencias}


Alviar García, Helena (coord.), Perspectivas contemporáneas en la Investigación Jurídica, Universidad de los Andes, Bogotá, 2012.

Barba, Andrés y Montes, Javier, La ceremonia del Porno, Anagrama, Barcelona, 2007.

Baudrillard, Jean, De la seducción, Cátedra, Madrid, 1998.

Bonilla, Daniel, Teoría del derecho y trasplantes jurídicos, Siglo del Hombre, Bogotá, 2009.

Deleuze, Gilles y Guattari, Felix, Mil Mesetas, Capitalismo y esquizofrenia II, Pretextos, Valencia, 1997.

Fitzpatrick, Peter, El derecho como resistencia: modernismo, imperialismo, legalismo, Siglo del Hombre, Bogotá, 2010.

Jurado, Fabio (coord.), Anfibios académicos, Pedagogías, docencia y evaluación en la educación superior, Universidad Nacional, Bogotá, 2012.

Kahn, Paul, El análisis cultural del derecho, una reconstrucción de los estudios jurídicos, Gedisa, Barcelona, 2001.

Latorre, Virgilio, Bases metodológicas de la investigación jurídica, Tirant lo Blanch, Valencia, 2012.

MacKinnon, C., Posner, R., Derecho y pornografía, Siglo del Hombre/U. de los Andes/Pensar, Bogotá, 1997. 
Martinez Neira, Manuel y Puyol Montero, José María, El doctorado en Derecho 1930-1956, Dykinson, Madrid, 2008.

Morin, Edgar, El Método I, La naturaleza de la Naturaleza, Cátedra, Madrid, 1997.

Morin, Edgar, El Método IV, Las ideas, su hábitat, su vida, sus costumbres, su organización, Cátedra, Madrid, 1998.

Patiño Gonzáles, María Cristina, Metodología de la Investigación, Manual para la elaboración de proyecto de Investigación de Maestrías y Doctorados, en proceso de publicación, USTA, Bogotá, 2013.

Rodríguez, César, Investigación anfibia: la investigación-acción en un mundo multimedia, Dejusticia, Bogotá, 2013.

Sloterdijk, Peter, Esferas III (Espumas), Siruela, Madrid, 2009.

Twining William, Derecho y Globalización, Siglo del Hombre/U. de los Andes/l. Pensar, Bogotá, 2003.

Viveiros de Castro, Eduardo, Metafísicas caníbales, líneas de antropología posestructural, Katz, Madrid, 2010.

Wajcman, Gérard, El Ojo absoluto, Manantial, Buenos Aires, 2011.

Zizek, Slavoj, El acoso de las fantasías, Siglo XXI, México, 2009.

Documentos institucionales de la USTA: 
VALENCIA V., DAVID (2013): “DRAGONES, CREATIVIDAD Y GENERACIÓN DE CONOCIMIENTO: UNA CONSIDERACIÓN MODULAR SOBRE LA INVESTIGACIÓN EN LA FACULTAD DE DERECHO”, VIA INVENIENDI ET IUDICANDI, VOL. 8, No. 2, PP. 110-136

Proyecto Investigativo Institucional- PROIN, Bogotá, 2005.

Revista Módulos siglo XXI, Núcleos problemáticos, Facultad de Derecho, N²-47, Bogotá, 2002.

Módulos №54, La Evaluación en la Facultad de Derecho, Bogotá, 2006. 